\title{
LAUBERER, Mathias, BRÄNDLE, Fabian, LEUTERT, Sebastian, Mein haußbiechlein. Schreibende Schuhmacher im 17. Jahrhundert
}

\section{Claire Gantet}

\section{(2) OpenEdition \\ Journals}

Édition électronique

URL : http://journals.openedition.org/ifha/818

DOI : 10.4000/ifha.818

ISSN : 2198-8943

Éditeur

IFRA - Institut franco-allemand (sciences historiques et sociales)

Référence électronique

Claire Gantet, «LAUBERER, Mathias, BRÄNDLE, Fabian, LEUTERT, Sebastian, Mein haußbiechlein. Schreibende Schuhmacher im 17. Jahrhundert », Revue de I'IFHA [En ligne], Date de recension, mis en ligne le 01 janvier 2005, consulté le 22 septembre 2020. URL : http://journals.openedition.org/ifha/818 ; DOI : https://doi.org/10.4000/ifha.818

Ce document a été généré automatiquement le 22 septembre 2020.

(CIFHA 


\title{
LAUBERER, Mathias, BRÄNDLE, Fabian, LEUTERT, Sebastian, Mein haußbiechlein. Schreibende Schuhmacher im 17. Jahrhundert
}

\author{
Claire Gantet
}

1 Ce diaire écrit par Mathias LAUBERER et son fils, cordonniers dans la ville allemande puis française de Colmar de 1657 à 1673, est édité dans la collection lancée par Kaspar von Greyerz et Alfred Messerli dans le cadre d'un programme d'édition de diaires rédigés dans les cantons helvétiques et l'Allemagne méridionale entre 1500 et 1850 . Le petit livre est muni d'une introduction détaillée sur l'itinéraire de Mathias Lauberer père, baptisé catholique mais éduqué par des beaux-parents protestants dans la ville majoritairement protestante de Colmar, durant la guerre de Trente ans. Dans une ville qui, à partir de 1635 s'emploie à résister à une influence française de plus en plus insistante jusqu'à l'occupation directe, en 1673, par les troupes de Louis XIV, Lauberer père est un artisan installé : après un long voyage d'apprentissage, il est devenu membre d'une corporation et a acquis un atelier.

2 Parmi les livres de raison, le diaire se caractérise par l'absence de notations de transactions marchandes. Empruntant au genre de la chronique, Lauberer père et fils couchent par écrit avant tout ce qui dévie du quotidien : orages, périodes de cherté, récoltes exceptionnelles, maladies (et recettes de médicaments). Leurs notations véhiculent aussi leurs cercles et relations sociales, mais aussi, de façon plus singulière, les problèmes matrimoniaux au sein du couple.

3 L'édition de ce diaire est faite de façon très soignée. On peut même être frappé par le contraste entre l'érudition mobilisée tant dans l'introduction de F.B. que dans l'apparat critique déployé par F.B. et S.L., et le diaire lui-même, constitué de notes égrenées sur une cinquantaine de petites pages. À l'issue de la lecture, on se demande en quoi un tel document contribue au projet de la collection, défini comme une enquête sur la perception du moi et son évolution, depuis la présentation de la personne extérieure à 
une conception cohérente de l'individu. Les volumes ultérieurs de la collection apporteront sûrement des pièces supplémentaires à la problématique du moi et de l'identité, à moins que le genre du diaire en lui-même ne suffise pas à répondre à une telle question.

Claire GANTET (Université Paris I-Panthéon-Sorbonne/

5 Historisches Kolleg, Munich) 